\title{
Applying environmental policy instruments to used oil
}

W. David Conn, Department of City \& Regional Planning, Cal Poly, San Luis Obispo

\begin{abstract}
A comprehensive assessment was conducted of California's Used Oil Program, which was established in 1992 to reduce the illegal disposal, and promote the reuse, of used lubricating oil. This paper summarises selected key findings of the assessment and discusses them in the context of designing and implementing policy instruments for promoting environmentally responsible waste management. The approach known as 'community-based social marketing' is identified as a promising option.
\end{abstract}

Keywords: used oil; recycle; policy instrument; California; reuse; community based social marketing 


\section{Introduction}

Used oil from motor vehicles and other sources can contain such relatively toxic substances as benzene, lead, zinc and cadmium (US Department of Health and Human Services 1997). Its improper disposal is considered by the US Environmental Protection Agency (1989) to pose a risk to human health and the environment through, for example, the possible contamination of aquifers and other sources of drinking water. California law prohibits the disposal of used oil "by discharge to sewers, drainage systems, surface water or groundwater, watercourses, or marine waters; by incineration or burning as fuel; or by deposit on land" (Health \& Safety Code $\$ 25250.5$ (a)). Nevertheless, in 2002, it was estimated that approximately 13 million gallons of used oil were unaccounted for in California and "possibly improperly disposed of down storm drains, into lakes or streams, or thrown in the garbage" (California Integrated Waste Management Board 2002).

Under the mandate of California Oil Recycling Enhancement (CORE) Act (Public Resources Code [PRC] sections $\S \S 48600-48691)$, the state's Integrated Waste Management Board (CIWMB) created the Used Oil Program (UOP). The statute called for the establishment of local collection programmes that encourage the recycling of used oil and decrease the illegal disposal of used oil, to be achieved largely through the award of annual block grants to local governments. Block grants are sums of money awarded with only general provisions as to how they must be spent, in contrast to categorical grants that must be spent in more tightly specified ways.

In October 2002, California Polytechnic State University (Cal Poly) was awarded a contract by the CIWMB to conduct a comprehensive overview and assessment of the UOP's accomplishments and impacts in the 10 years (at that time) since it was established. First published by the CIWMB in February, 2005, the results were intended to assist in the development of a work plan for the UOP, streamlining the oil grant administration process, and providing future options that could be implemented to increase used oil recycling capture rates.

This paper summarises some of the key findings of the assessment and discusses them in the context of designing and implementing policy instruments for promoting environmentally responsible waste management. The various ways in which the CORE Act has been implemented are analysed under the categories of 'command and control', 'economic incentives/disincentives', and 'information/education'. The approach known as 'community based social marketing', which typically incorporates elements of the second two categories, is identified as a promising option. 


\section{Approach and methodology of assessment}

Cal Poly's research team (comprising faculty, graduate students and a consultant) assessed the UOP at several levels, corresponding to different levels of articulated or assumed goals and objectives. At the first level was the 'instrumental objective' of implementing a number of programme components required by the CORE Act, including a recycling incentive system, a network of certified collection centres, noncompetitive (block) and competitive grants, an information and education system, and a reporting, monitoring and enforcement programme. The team considered achieving effectiveness and efficiency in the implementation of these components to be 'instrumental', since they are not an end in themselves but rather a means to accomplishing the programme objective and, ultimately, the overall goal of the programme.

At the second level was the 'programme objective' which, according to the statute, is that of reducing the illegal disposal of used oil and recycling/reclaiming used oil "to the greatest extent possible" (PRC $\S 48600)$.

At the third level was the 'ultimate legislative goal', which, based on the Legislature's stated purpose in the CORE Act, was understood to be the recovery of valuable natural resources and the avoidance of damage to the environment and threats to public health.

The study was conducted by reviewing relevant documents and conducting interviews with, or directing written inquiries to, a broad range of individuals. These including Board members, former and present UOP staff, others associated with the development of the UOP (such as former legislative staff), grantees, staff of professional associations representing grantees (such as the League of California Cities), operators of certified used oil collection centres, officials of other entities (including non-profit and for-profit corporations) involved in collecting and recycling used oil, staff in other California State agencies (notably those administering grant programmes that are similar in some respects to those for used oil), staff in other states' used oil programmes, and others generally knowledgeable about pollution issues in California.

Approximately 80 interviews were conducted, mostly in-person, but some by telephone. The typical length of in-person interviews was between 30-60 minutes. Questions were pre-defined for each category of respondent, but interviewers were given latitude to probe as they felt appropriate or to pursue unanticipated but potentially informative lines of inquiry. Notes were taken, but interviews were not taped out of concern that government employees, in particular, might be hesitant to answer questions fully and 
accurately if recorded. Whenever possible, the team sought to triangulate the findings using discrete sources of information, e.g. written documents prepared by different agencies, responses from individuals independent of one another, etc.

While an effort was made to seek input that might be considered reasonably representative, the scope of the project did not allow for statistically significant results to be obtained through the systematic surveying of respondents. In other words, much of the input was anecdotal and, as such, was considered suggestive rather than definitive. For this reason, some of the recommendations called for further research before significant action might be taken to change the programme.

\section{Major provisions of the CORE Act}

The intent is "to reduce the illegal disposal of used oil and recycle and reclaim used oil to the greatest extent possible in order to recover valuable natural resources and to avoid damage to the environment and threats to public health" (PRC $\$ 48600)$.

\subsection{Used oil recycling fund}

Oil manufacturers are required to pay the Board 16 cents for every gallon of lubricating oil sold, transferred or imported for use in California. Revenues are used:

- To make annual block grant awards to local jurisdictions on a per capita basis for the development and support of local used oil collection programmes;

- To pay a recycling incentive of no less than 16 cents per gallon to members of the public and others for the collection and recycling of used lubricating oil;

- To establish an annual reserve, to pay for Board administration of the programme, and to pay for the reporting and inspection of used oil haulers and facilities by the Department of Toxic Substances Control (DTSC); and

- To provide appropriations for statewide outreach, competitive grants, and other purposes.

\subsection{Certified used oil collection centres}

Certified used oil collection centres (CCCs) are to be established that comply with certain requirements relating to operating hours, publicity, maximum quantities of oil accepted, etc. A CCC must offer to pay a recycling incentive of 16 cents per gallon to any person who brings to the centre used lubricating oil in containers. (The Act does not specify what should happen - and the team has no evidence on what does happen - to the containers themselves, which are thought to be typically returned empty to the people bringing them in.) However, an individual may donate used oil to the CCC or the centre may offer the 
person a credit of at least twice the recycling incentive that may be applied toward the purchase of goods or services offered by the centre.

\subsection{Grants and contracts}

Block grants are awarded on a largely per-capita basis (with an enhancement to reflect minimum levels of funding needed by small and rural jurisdictions) to help local governments establish or enhance permanent, sustainable used oil recycling programmes involving, for example, used oil and filter collection. In fiscal years 2000-01, 2001-02 and 2002-03, block grants were awarded totalling approximately $\$ 12$ million, $\$ 11$ million and $\$ 16$ million, respectively.

Competitive grants include:

- Opportunity grants, which provide additional funding to local governments to augment or expand oil collection and outreach/education programmes established by the block grants.

- Non-profit grants, which are awarded to non-profit organizations for used oil and used oil filter recycling projects.

- Research, testing and demonstration (RT\&D) grants, which are awarded to entities pursuing research, testing and demonstration projects for collection technologies; for developing uses for products resulting from the recycling of used oil; and for education and mitigation projects relating to stormwater pollution from used oil and oil by-products.

In fiscal year 2000-01, approximately \$3 million was awarded in non-profit grants; in 2001-02, \$5 million in opportunity grants; and in 2002-03, \$4 million in non-profit and RT\&D grants.

As appropriate, the UOP also awards contracts specifying particular deliverables, e.g. for the comprehensive assessment on which this paper is based, for a statewide survey and analysis of 'Do-ItYourselfers' conducted by San Francisco State University (SFSU), and for a number of education/outreach initiatives such as the development of two major curricular packages intended for grades K-6 and 6-12, respectively.

\section{Results of the assessment}

\subsection{Instrumental objectives}

The team concluded that, after being in existence for a little more than 12 years (by the end of the study), the UOP had succeeded in meeting the instrumental objectives specified in the CORE Act. It had:

- Implemented a recycling incentive; 
- Set in place a network of certified and non-certified collection centres throughout the state that collects millions of gallons of used oil each year (see Tables 1 and 2);

- Established a statewide used oil recycling outreach and education programme; and

- Channelled substantial funding to local jurisdictions, non-profits and others through a block grant programme and several competitive grant programmes.

In 2004 the number of CCCs had stabilised at approximately 2600 (CIWMB 2004), although about 3100 service stations, auto parts stores and fast-lube operations (i.e. firms specialising in rapid oil changes and lubrication) had previously been recruited to perform this function. When asked, $77 \%$ of the operators of facilities that had withdrawn from the programme since its inception either gave no reason for leaving or indicated business closure or change of ownership as the reason for withdrawal. The remaining $23 \%$ cited problems with the programme itself, such as:

- 'Hassle factor' (e.g. having to give out the recycling incentive, after-hours oil drop off, contamination of the collected used oil, DIYers interfering with business, poor relationship with local jurisdiction or claim reimbursement problems);

- 'Space/tank issues' (e.g. inability or unwillingness to provide space for storing used oil or failure of locality to supply free tank as promised); or

- 'Cost' (e.g. expense of oil hauling, employee labour, tank or drum, or disposal of contaminated oil) (CIWMB 2004).

Despite ongoing efforts by the programme staff to streamline administrative processes, the team heard complaints during the interview process from some grantees with regard to, for example, the timetable for preparing and submitting grant applications; what has to be included in these applications, such as the specification that applicants provide authorising resolutions from governing bodies covering, at a minimum, the period of the grant cycle (three years for block grants); restrictions on administrative cost reimbursement; reporting requirements, including the need to certify compliance with the state's procurement rules addressing recycled content; and the withholding of $10 \%$ of funds until the entire allocation for a particular grant cycle has been spent.

A review of these complaints suggested that, in some cases, respondents were unaware of improvements already made or planned. In other cases, based largely on a comparison of the UOP's expectations with those of other state agencies administering comparable grant programmes (as well as on what the team considered reasonable, taking into account the need to safeguard the use of public funds), it was concluded that the former were not unduly demanding. Indeed, the team believed that, for the most part, 
the staff had done a good job of minimising the information required and presenting the materials in a straightforward and understandable manner.

\subsection{Programme objective}

By establishing a used oil collection infrastructure and collecting over 600 million gallons (estimated) of used lubricating oil since 1993, the UOP had made reasonably good progress toward the programme objective of reducing the illegal disposal of used oil as well as recycling and reclaiming used oil 'to the greatest extent possible'. The total amount of used oil collected prior to the UOP's introduction is unknown because it was not measured. However, as indicated in Table 1, the volume of used oil collected annually by public collection programmes since the mid-1990s (when the UOP began making measurements) appears to have grown almost every year. Statewide surveys suggest that the Do-ItYourselfer (DIYer) sector as a proportion of all California households (although not as an absolute number) probably decreased during the programme's existence, dropping to about $17.6 \%$ by 2001 (SFSU 2005). Nevertheless, CIWMB data based on reports from collection centres suggest that the total amount of used oil returned by DIYers for recycling remained steady (and may have increased). This is significant because of the assumption that DIYers are the people most likely to dispose of used oil illegally. So-called 'shade tree mechanics' (individuals, typically unlicensed and unregulated, who change oil for family and friends), small rural growers and independent truckers in rural areas are aggregated with other DIYers in this context (SFSU 2002, 2005).

\subsection{Ultimate legislative goals}

What is less sure is the extent to which the UOP had achieved the programme's ultimate legislative goals, one of which is the conservation of natural resources. While the increase in recycling undoubtedly signifies that more is being conserved than before, at present most of the recovered oil is ultimately reprocessed for bunker fuel rather than re-refined oil, even though re-refining is generally acknowledged to be more conserving and less of a risk to public health and the environment (Boughton and Horvath 2004). Furthermore, until recently, California's used oil programme gave relatively little attention to the possibility of reducing the rate at which used oil is generated, i.e. to pollution prevention rather than collection and recycling. Since the publication of the team's report, which recommended greater emphasis on pollution prevention, the UOP has begun a campaign to encourage longer intervals between oil changes in passenger vehicles (California State University, San Marcos 2007).

What is most difficult to assess is the degree to which the programme has succeeded in avoiding damage to the environment and threats to public health by reducing illegal disposal. The reality, it seems, is that nobody knows for certain how much, if any, environmental or health damage was caused by illegal oil 
disposal before the UOP was established, or how much damage it has created since. Given the nature of used oil and the quantities unaccounted for (as previously mentioned, approximately 13 million gallons in 2002), there is certainly reason to suppose that illegal oil disposal poses serious risks, but the team's knowledge base in this area is very incomplete.

\section{Use of policy instruments}

Policy instruments have often been placed, especially by economists, in categories such as 'command and control', 'economic incentives/disincentives' and 'information/education'. Command and control instruments specify what is to be accomplished and/or how it is to be accomplished, using the threat of legal sanctions (e.g. fines, imprisonment) to achieve compliance. Economic incentives may be used to encourage desirable behaviour (e.g. through subsidies) or to discourage undesirable behaviour (e.g. through taxes or charges), while giving the targeted entity flexibility to respond in its own best interest. The principle behind information/education as a policy instrument is that people will behave in desirable ways if only they have the information they need to know what is desirable and why.

The UOP has sought to achieve its objectives using a combination of instruments, as categorised in Table 3.

\subsection{Command and control}

Although federal law provides for the possibility of managing used oil under less stringent regulations than those applying to hazardous wastes generally, California has opted to define used oil as a hazardous waste and to implement the more stringent standards (presumably, believing these to be necessary for protection of human health and the environment). In most instances, this means that the generator must contract with a registered hazardous waste transporter to have the used oil picked up within the appropriate accumulation period. The transporter must take the oil to an authorised used oil storage or treatment facility. Persons or businesses generating used oil are required to meet all used oil generator requirements, as are used oil collection centres. Although householders who change their own oil (Do-ItYourselfers) are exempted from regulation as used oil generators, California's definition of used oil as a hazardous waste affects them indirectly because it raises costs and tends to reduce the willingness of companies to participate in collection programmes (the preferred option for DIYers to dispose of their used oil).

DIYers are more directly affected by the explicit prohibition in California law (previously mentioned) of anyone disposing of used oil to land, water, storm drains, etc. Like other command and control 
approaches, this prohibition is very direct in its specification of non-permitted behaviours. However, in common with many approaches of this kind, a key problem is enforcement (see, for example, Russell 1990, Davies and Mazurek 1998). It is very difficult to catch DIYers actually engaging in illegal behaviour. According to UOP staff and other professionals involved in the management of used oil, enforcement of the ban is rare, although "nobody has ever kept track of enforcement actions for illegal disposal of used oil in any coherent manner. CIWMB and DTSC (the California Department of Toxics Substances Control) do not keep those records" (email communication, California UOP, 8 May 2008). From an individual DIYer's perspective, it appears that the chances of being caught are almost

infinitesimally small. A significant number evidently comply anyway, in part (perhaps) because they want to do the 'right thing,' but it is believed that many others do not. Based on survey data, Rufus Browning and his team at SFSU (2005) estimated that at least 1.072 million gallons of used motor oil, or close to $5 \%$ of all such oil disposed of in 2003-04, were buried or poured on the ground or allowed to enter a drain or gutter, while as many as 12.765 million gallons (just under $60 \%$ ) were thrown in the trash.

Not only does this approach by itself appear to be ineffective as a deterrent to improper disposal, it may actually work against the goals of the UOP programme by making it significantly more difficult and expensive to handle the used oil once collected. Because the potential liability associated with handling used oil in California is much higher than in other states where used oil is not classified as a hazardous waste, companies may be less likely to agree to serve as collection centres.

\subsection{Economic incentives}

\subsubsection{Recycling incentive}

The UOP pays a recycling incentive of 16 cents per gallon to CCCs that collect used oil from the public and ship it for recycling. In turn, each CCC is required to pay, or at least offer, the 16 cents per gallon incentive payment to members of the public who bring in their used oil. However, anecdotal evidence (obtained in interviews with UOP staff as well as centre operators) suggests that in practice CCCs often neither offer nor pay the 16 cents per gallon incentive to members of the public unless they specifically request it. CCCs actually have a disincentive to offer the incentive payment to the public because, when the public fails to claim it, the money remains with the centre. Since CCCs are given no other financial support for their participation in the programme, the revenue from unclaimed incentive payments is important in helping to offset labour, storage and hauling costs associated with used oil collection. Without this revenue, more CCCs might be expected to drop out of the programme.

Assuming that the collection centre actually offers the recycling incentive payment, some interviewees in the study here questioned whether the amount is large enough to motivate DIYers to recycle their oil. This amount is so small that the public might not take the trouble to request it even if they knew of their 
entitlement. In many cases, it seems that DIYers are simply pleased to have a location at which they can discard their used oil. Survey results suggest that, at the incentive's current rate, convenience (such as perceived distance to the nearest collection centre) or knowledge of used oil's environmental impacts are more of a motivator for DIYers to bring in used oil than the incentive payment (SFSU 2002, 2005). It appears that the incentive would have to be much larger in order to make a significant difference in oil recycling behaviour: " 44 percent thought an incentive of $\$ 1.00$ per gallon would do it; 56 percent named amounts from \$2 to \$4 per gallon and up" (SFSU 2002, p. 34).

In addition to paying reimbursement claims to CCCs for the oil they collect from the public, the CIWMB also pays the recycling incentive of 16 cents per gallon (if claimed) for used oil generated on-site, e.g. for oil drained from customers' vehicles by fast-lube businesses and auto repair shops. Precisely how much DIYer-generated oil is collected by these entities is unknown because they often mix the oil from their oil-change customers and DIYers together in the same tank.

Several interviewees suggested eliminating incentive payments to CCCs for oil they generate internally, since the centres are required to recycle this oil anyway. They could track and claim the payment on DIYer oil alone, e.g. by collecting the oil from different sources in separate drums or tanks or by having DIYers sign a log of used oil brought in. However, there is a risk that many fast-lube and auto repair facilities, which constitute almost half of the total CCCs in the state, might leave the programme if these payments were eliminated. Some might continue as CCCs for public relations or marketing purposes, but it is not possible to predict how many. The loss of these facilities from the programme, while reducing convenience for the public, might not be too serious given the estimate by the UOP staff (based in part on the SFSU research) that only 1-3\% of DIYer used oil statewide is collected at fast-lubes, although a larger proportion (around 10\%) may be taken to auto repair shops. Additional concerns are that elimination of the payments might cause these businesses to be less supportive politically and less likely to promote the use of re-refined oil to their customers.

Auto parts stores constitute the largest sector of CCCs (1036) and differ from fast-lube and auto repair CCCs in that they collect a much larger volume of used oil from DIYers while generating no used oil internally. Auto parts stores have a greater financial incentive to participate because DIYers who bring in used oil are likely to shop for other goods and services, e.g. a study found that DIYers on average made purchases of \$13 per visit (CIWMB 2004). In some other states, such as Florida, auto parts stores accept used oil from the public without paying an incentive. The amount of used oil collected annually from DIYers in Florida, divided by the state's population, is approximately 0.18 gallons per capita, whereas the equivalent number for California is not greatly different, at about 0.26 gallons per capita. A number of factors are thought to contribute to Florida's success in collecting used oil despite the lack of a financial 
incentive, most notably the fact that used oil is not defined as a hazardous waste in that state (Florida Department of Environmental Protection 2007).

\subsubsection{Grant programmes}

From the beginning, consistent with the CORE Act, the UOP has employed its grant programmes - both block and competitive - as the primary tools to bring about the diversion and recycling of used oil. Both former and present staff stated that 'getting the funds out' had been (and still was) high on their list of objectives, if not at the very top. In practice, they had been successful in doing just that, awarding a total of $\$ 167,107,912$ in 10 years, of which $\$ 145,626,027$ had been spent (as of the end of fiscal year 2003). On average, the UOP had disbursed $\$ 16.7$ million each year, of which a minimum of $\$ 10$ million had to be given to local government as non-competitive grants (PRC §48653).

The statute requires the Board to disburse block grant funds directly to the local jurisdictions. The underlying philosophy is that of enabling these jurisdictions, individually or in collaborative arrangements with others, to establish used oil collection programmes most suited to local circumstances, based on local knowledge. It also reflects the belief that, in order to be effective in persuading DIYers and others to participate in these programmes, education and outreach must be conducted at the community level. A major challenge faced by the UOP has been that of designing and implementing an administrative system that achieves a balance between:

- Giving sufficient direction to grantees to maximise the likelihood that even those with the least expertise and/or commitment will achieve the statewide goals of preventing the improper disposal of used oil and causing it to be recycled instead;

- Giving sufficient latitude to grantees to pursue these goals most effectively and efficiently, given their knowledge of local circumstances;

- Allowing grantees and UOP staff to 'get on with it,' with the focus on programme implementation and continuous improvement, not administrative paperwork; and

- Achieving adequate accountability so that the UOP can maintain its fiduciary responsibility to ensure that public funds are properly spent.

Recipients of block grants are largely left to establish their own goals, objectives and activities, within constraints on allowable expenses set by the UOP, which also offers technical assistance. On the other hand, those receiving competitive grants receive more direction in the form of 'programme criteria' established prior to each grant cycle and used in scoring applications. These recipients are expected to apply their own knowledge, skills and creativity in furthering the goals of the UOP, based on the criteria. 
Grantees are expected to file regular reports about their programmes. However, in past years little attempt was made to make systematic use for programme improvement of the information submitted in these reports, beyond tracking the quantities of used oil and filters collected (some of which came from the UOP staff themselves). The UOP staff workload and impact of budget reductions were such that not much time was available for conducting more extensive analysis. Furthermore, beyond occasional profiles of grantee programmes in the intermittent 'Used Oil and Household Hazardous Waste Grants Bulletin' and the publication of a limited selection of project reports (often some time after completion), information was not readily available to those outside the UOP itself. For example, the used oil website listed brief project descriptions for several cycles of research, testing and demonstration grants, but gave no indication of the results of these projects or where results might be found.

In 2003, after the start of the study reported here, UOP staff began analysing grantee programme data to determine which programmes and programme delivery methods had achieved the highest rates of per capita used oil collection and why. Upon the completion of this assessment, staff planned to share the results of the analysis with grantees and encourage them to adopt and customise practices that had proved most successful. Staff also stated that they would re-organise the UOP website and post profiles of successful grantee programmes from each grant cycle. Indeed, a new set of pages entitled Profiles of Model Used Oil/HHW Projects (providing information about both used oil and household hazardous wastes) has now been added to the website, but so far only a very small number of projects have been featured.

\subsection{Information/education}

Information/education is included as a policy instrument to inform people about both the risks of improper disposal of used oil and the options available for collection and recycling. The SFSU (2005) study revealed that knowledge of specific environmental impacts of used oil reduces improper disposal among some DIYers.

Responsibility for outreach and education has been shared between the UOP and individual grantees, with the bulk of the effort implemented by the latter. The UOP currently maintains for viewing both a physical and a web-based library of outreach and educational materials that grantees and contractors have developed using Board funding. At the time of the study, these were not downloadable and copies could be obtained only by contacting the original grantees, but many are now accessible on the Board's website. For the most part, confidence in the effectiveness of these efforts has to be a matter of faith, since assessment of outcomes (e.g. increased recycling behaviour linked to the efforts themselves) is difficult to accomplish and has generally been lacking. This applies especially to education aimed at school children 
(who, it is hoped, will influence the behaviour of older relatives while developing an inclination toward environmentally sound behaviour of their own in the future). Furthermore, the assessment revealed significant problems with efforts in the schools because of the difficulty of persuading teachers to use curricular materials unrelated to the educational standards for which they are increasingly held accountable through the regular testing of their pupils.

The largely decentralised nature of the UOP's outreach efforts can be contrasted with those of other state agencies' programmes such as the Department of Conservation's (DOC) bottle-can recycling programme and the Department of Consumer Affairs' energy conservation programme. Unlike the DOC, whose strategy is to reach multiple targets statewide with a single message and which spent over $\$ 10$ million to promote its 'Good for the Bottle and Good for the Can' campaign, the UOP does not have funding to conduct an equivalent statewide campaign. Grantees are not required to use common materials or even the same message (although they are required to display the 'oil drop' logo and acknowledge Board funding). Consequently, there is not a strong common message statewide.

\section{Discussion}

The assessment here of California's Used Oil Programme reinforces much of what we already know, or have suspected, about the use of various policy instruments to promote environmentally desirable behaviours (see, for example, US Congress, Office of Technology Assessment 1995, Fiorino 1995, Salzman and Thomson 2006, Rosenbaum 2008).

In relation to the recycling of used oil by DIYers, the command and control approach has limited usefulness. In California, bringing used oil to a collection centre (or having it collected) is essentially the only legal method of handling it, since it cannot be dumped on the land, in waterways, into sewers or into the trash. However, because of the difficulties of enforcement, there is virtually no chance of an individual DIYer being caught and punished for improperly disposing of used oil. Thus, compliance in almost all cases is purely voluntary, if at all.

Of the economic incentives included in the UOP, the recycling incentive of 16 cents per gallon is the most direct, at least in theory, in that its targets include the DIYers themselves (i.e. those most likely to dispose of used oil improperly). However, even when the incentive is offered (which seems to happen inconsistently), the amount is so small that it appears to have little or no impact on DIYers' behaviour. How large it would need to be in order to produce an appreciable difference in behaviour remains speculative; even if it were set at a level comparable to the price of 'new' oil, it might still be insufficient (at least by itself) to get people to act differently. In practice, setting the incentive this high is most 
unlikely, for a variety of reasons; for example, one might anticipate that it would result in attempts to inflate the quantities of used oil collected (e.g. by contaminating the oil with other fluids), while CCCs might be further encouraged to hang on to the incentive funds rather than to pay them out.

An important finding of the study is that a substantial amount of the incentive funding ends up in the pockets of businesses such as fast-lubes and auto-repair shops which would almost certainly recycle their used oil anyway. However, ending this practice might not only cause a reduction in the number of CCCs (which may not be a major issue), but also place in jeopardy the entire statewide programme due to the potential loss of these firms' political support - or worse, their active opposition.

Compared to the amount going toward the recycling incentive, a much larger amount of the monies generated by the fee on the sale of 'new' oil currently goes into the UOP's grant programmes. These provide indirect incentives for the recycling of used oil, since they fund localities and other entities to implement their own programmes targeted at DIYers and other used oil generators, as well as supporting research, development and demonstration. Although these programmes appear to have been reasonably successful to date in increasing the quantity returned for recycling, it seems that a significant amount of used oil is still improperly disposed of.

It is thought that part of the problem is the fact that the law provides for little or no accountability for good performance (meaning effectiveness in promoting used oil recycling) since the block grants are essentially entitlements. In addition, little or no learning has taken place because of a failure, at least in the past, to analyse or share with others the results of grantees' initiatives. Thus potential opportunities for improvement have been lost.

Finally, the UOP has included education and outreach both at the statewide level and, more extensively, at the level of individual localities, but the effectiveness of these efforts remains largely unknown. There are possible problems with the efforts themselves (e.g. the difficulty in getting school teachers to adopt UOP's curricular materials; a lack of sharing of best practices between localities; the absence of a strong common message statewide) and there has been little or no assessment of outcomes.

\subsection{Community-based social marketing}

During the past few years the CIWMB has started to invest in a 'new' approach, known as 'communitybased social marketing' (CBSM), to foster responsible behaviour on the part of DIYers who might otherwise dispose of used oil improperly. CBSM is an "approach in which promoters identify the activity to be promoted and the barriers to this activity and then design a strategy to overcome these barriers, using psychological knowledge regarding behaviour change" (McKenzie-Mohr 2000, p. 531). As an example, a team led by Wesley Schultz recently conducted a pilot project in Los Angeles in which the 
lack of proper oil containers was identified as a barrier to the use of collection centres by DIYers; subsequently, at stores distributing free containers with specially designed motivational stickers, significantly more oil was collected in a three-month trial period than at stores distributing containers with standard stickers or not distributing containers at all (California State University, San Marcos 2006, Tabanico and Schultz 2007).

\subsubsection{History and development of CBSM applied to waste management}

Interest in finding new ways of modifying Californians' behaviour with regard to waste generation and management actually goes back nearly 30 years. In 1980, for example, the State Solid Waste Management Board, a precursor of today's CIWMB, held a workshop on source reduction (now more commonly known as pollution prevention) that featured several presentations on the topic of social marketing, with examples of applications already attempted in the Bay Area (Conn 1980).

A major factor underlying the social marketing approach to environmental protection, and influential in the planning of the workshop, was the work of psychologists such as E. Scott Geller who contend that "the behavioural community psychologist should play a major role in the development, implementation, and evaluation" of programmes promoting waste reduction and resource recycling (Geller 1980, p. 55, see also Geller and Lehman 1986). Drawing on B.F. Skinner's approach to behavioural science (e.g. 1938, 1953), Geller and others have conducted experiments during the past three decades or more that demonstrate how community members' behaviour can be altered in environmentally desirable ways by suitably designed interventions. Examples of interventions, often used in combination, include signs and leaflets that prompt a desirable behaviour; modelling the behaviour via a videotaped demonstration; seeking a written or verbal commitment to perform the behaviour; making the behaviour more salient or convenient through the design of devices such as recycling containers; providing monetary or other rewards for performing the behaviour; and providing feedback regarding the beneficial consequences of the behaviour (e.g. notification that the quantity of material recycled has increased) (Lehman and Geller 2004).

As Geller himself bemoans, however, use of the behaviour-change approach by environmental policy makers has been quite limited to date, in part due to "a sparse supply of comprehensive, long-term behaviour-change projects in the environmental protection domain", but also because of inadequate dissemination of the 'technology' (Geller 1989, p. 19). As often as not, researchers in community behavioural psychology have shared their results among themselves, by publishing in scholarly journals, but have not made these results readily accessible to policy makers.

Despite the interconnections, the literatures on behavioural community psychology and social marketing have proceeded along rather separate tracks. In the 1980s and 1990s, the social marketing approach was 
applied sporadically to encourage recycling, but its most visible applications were in the fields of energy conservation and public health (e.g. Winett et al. 1985, Rocella et al. 1986, Rhodes and Shaughnessy 1989). However, in 1999 McKenzie-Mohr and Smith published a small volume entitled 'Fostering Sustainable Behaviour' which made readily accessible to practitioners the strategies and methods that are characteristic of what they call CBSM (McKenzie-Mohr and Smith 1999). A few years later, the CIWMB awarded to California State University, San Marcos (CSU-SM), a contract to conduct several CBSM used oil pilot projects, one in Los Angeles (mentioned above) and others in Napa and Madera counties.

The project in Napa County included the redesign of direct mail brochures to better inform and motivate residents to participate in the county's kerbside collection. In areas with the intervention (compared to areas without), enrolment in the programme significantly increased, as did the number of kerbside oil pick-ups (by 248\%) in the month following. As part of the Madera County project, DIYers were given one of three packets containing different mixes of incentives, some including a free oil funnel affixed with an oil recycling pledge sticker. Subsequently, the study revealed that "receiving a free funnel increased DIYers' reported intent to recycle their used oil but the additional pledge sticker did not further increase this intent level" (CSU-SM 2006, p. 2).

In the project's final report, the authors claimed that the empirical results from Los Angeles, Napa, and Madera counties "suggest that the CBSM approach can effectively be used to change behaviour and promote oil recycling among DIYers" (CSU-SM 2006, p. 42). They drew attention to the variation in barriers across different jurisdictions, "necessitating the need for interventions tailored to each of the counties" (CSU-SM 2006, p. 42). This is consistent with the community-specific orientation of CBSM.

Scepticism about this approach was expressed by some of the UOP staff and grantees interviewed in the assessment here. Nevertheless, in the solicitation for its 2004/05 Used Oil RT\&D grants, the CIWMB sought projects that proposed to use social marketing techniques and awarded two grants for this purpose, both aimed at increasing used oil recycling. The target population in one case was shade tree mechanics among the immigrant population in Los Angeles; in the other case it was students in English as a Second Language (ESL) classes. The findings of these studies have not yet been published.

\subsubsection{CBSM as a policy instrument for the future}

CBSM cuts across the two non-coercive policy categories identified earlier in that it is likely to combine information/education with economic incentives, often adding 'prompts' to remind people to engage in desirable behaviours and/or building community support for such behaviour by the establishment of social norms. As a policy instrument that might be considered for broad application by a state agency (such as the CIWMB), it has the disadvantage of requiring - by its very nature - tailoring to each individual community; what is effective in one locality might be wholly ineffective in another. 
Accommodating such variations may be seen at the state level as administratively unwieldy and inefficient. Furthermore, there is evidence to suggest that the effects of a social marketing campaign may be short-lived. For example, in the CIWMB's Los Angeles pilot the desired change in behaviour appears to have ended once the intervention was withdrawn. Bloom and Novelli document other challenges facing the social marketing approach, but they conclude on a positive note, asserting that it can be successful if the problems they identify "are anticipated and dealt with in a creative and logical manner" (Bloom and Novelli 1981, p. 87).

In most contributions to the literatures on behavioural community psychology and social marketing, it is assumed that the sought-after behavioural changes (the 'ends') are desirable from a societal viewpoint, that the techniques used (the 'means') are fair and above-board rather than manipulative, and that there are no unintended negative side-effects. However, in his text on social marketing, Andreasen (1995, p. x) states: this marketing approach has an immense potential to affect major social problems if we can only learn how to harness its power - while, at the same time, taking care to use it for the good of society and not to advance particular parochial aims.

Buchanan et al. (1994) as well as Crane and Desmond (2002) are among others who also note that social marketing raises potential ethical concerns. At this point, as far as is known, the CIWMB's experimental use of social marketing to achieve the goals of the Used Oil Programme has not attracted scrutiny or criticism on this score.

Overall, recognising the limitations of other approaches used to date, the assessment here of California's Used Oil Program took an optimistic view of CBSM's potential as a policy instrument. The report included the following statement:

We believe that community-based social marketing offers a very promising approach to achieving the particular goals of the UOP, and we recommend that if the pilot projects provide evidence in support of this belief, the Board should actively encourage the wider implementation of CBSM by grantees and continue to include it as a programme priority. Furthermore, since most grantees currently lack expertise in social marketing techniques, the Board would also need to provide adequate training and support (such as literature, workshops, and possibly access to a qualified consultant who could provide technical assistance and troubleshooting for ongoing projects). (California Polytechnic State University 2005, p. 45)

The proviso about pilot project results is an important one, since more empirical evidence on the effectiveness of CBSM is required if its endorsement is to be justified. As previously mentioned, as part 
of its $04 / 05$ programme of RT\&D grants, the UOP funded two projects that explicitly incorporated CBSM. No fewer than five out of seven grants for Non-Profit Organizations awarded by UOP in 2004/05 mentioned CBSM in their project summaries, as did one Opportunity Grant awarded in 05/06.

Unfortunately, possibly due to a lack of resources for updating, the UOP website does not yet report the results of these projects or indicate when/where they might be available. It can only be hoped that the CIWMB will have the resources and inclination to move faster than it has done in the past to publish these results, which are potentially important not only for the UOP itself but also for others who are anxious to find out if the CBSM approach can deliver on its promise.

\section{Acknowledgements}

This paper draws from a 2005 report entitled Comprehensive Assessment of California's Used Oil Program, Publication No. 611-05-001, prepared by California Polytechnic State University, San Luis Obispo, under contract to the California Integrated Waste Management Board (available at http://www.ciwmb.ca.gov/Publications/default.asp?pubid = 1104). The Cal Poly research team comprised W. David Conn (Project Director), Anny Morrobel-Sosa, Dianne Long, Susan Opava, William L. Owens, Andrew Firestine, Andrea Koch, Brian Schwartz, Cristi Spahr and Zachery Thomas. An earlier version of the paper was presented at the 46th Annual Conference, Association of Collegiate Schools of Planning, Kansas City, Missouri (October 2005). Any opinions expressed in the paper are those of the author alone and do not represent the views of the California Integrated Waste Management Board or Cal Poly. 


\section{References}

1. Andreason, A. R. (1995) Marketing social change Jossey-Bass, San Francisco

2. Bloom, P. N. and Novelli, W. D. (1981) Problems and challenges in social marketing. Journal of marketing 45 , pp. 79-88.

3. Boughton, B. and Horvath, A. (2004) Environmental assessment of used oil management methods. Environmental science \& technology 38, pp. 353-358.

4. Buchanan, D. R., Reddy, S. and Hossain, Z. (1994) Social marketing: a critical appraisal. Health promotion international 9 , pp. 49-57.

5. California Integrated Waste Management Board (2002) California's used oil recycling program. Publication No. 332-97-015 California Integrated Waste Management Board, Sacramento, CA

6. California Integrated Waste Management Board (2004) Analysis of certified collection centers. Used Oil Program staff report California Integrated Waste Management Board, Sacramento, CA

7. California Integrated Waste Management Board (2006) Used oil recycling rate biannual report: fiscal year 2004-2005. Publication No. 611-06-016 California Integrated Waste Management Board, Sacramento, CA

8. California Polytechnic State University (2005) Comprehensive assessment of California's used oil program. Publication No. 611-05-001 California Integrated Waste Management Board, Sacramento, CA

9. California State University, San Marcos (2006) Community based social marketing pilot to increase do-it-yourself oil recycling rates. Publication No. 611-06-004 California Integrated Waste Management Board, Sacramento, CA

10. California State University, San Marcos (2007) Used oil source reduction study: 'busting the 3,000 mile myth'. Publication No. 611-07-003 California Integrated Waste Management Board, Sacramento, CA

11. Conn, W. D. (1980) Workshop on waste reduction: summary of proceedings California Integrated Waste Management Board, Sacramento, CA

12. Crane, A. and Desmond, J. (2002) Social marketing and morality. European journal of marketing 36 , pp. 548-569.

13. Davies, J. C. and Mazurek, J. (1998) Pollution control in the United States: evaluating the system Resources for the Future, Washington, DC 
14. Fiorino, D. J. (1995) Making environmental policy University of California Press, Berkeley, CA

15. Florida Department of Environmental Protection (2007) Florida's used oil recycling program. 22nd annual report Florida Department of Environmental Protection, Tallahassee, FL

16. Geller, E. S. Martin, G. L. and Osborne, J. G. (eds) (1980) Saving environmental resources through waste reduction and recycling. Helping in the community: behavioural applications pp. 55-102. Plenum Press, New York

17. Geller, E. S. (1989) Applied behavior analysis and social marketing: an integration for environmental preservation. Journal of social issues 45, pp. 17-36.

18. Geller, E. S. and Lehman, G. R. (1986) Motivating desirable waste management behavior: applications of behavior analysis. Journal of resource management and technology $\mathbf{1 5}$, pp. 58-68.

19. Lehman, P. K. and Geller, E. S. (2004) Behavior analysis and environmental protection: accomplishments and potential for more. Behavior and social issues 13, pp. 13-32.

20. McKenzie-Mohr, D. (2000) Fostering sustainable behaviour through community-based social marketing. American Psychologist 55 , pp. 531-537.

21. McKenzie-Mohr, D. and Smith, W. (1999) Fostering sustainable behavior: an introduction to community-based social marketing New Society Publishers, Gabriola Island, BC

22. Rhodes, T. and Shaugnessy, R. (1989) Selling safer sex: AIDS education and advertising. Health promotion 4 , pp. 27-30.

23. Rocella, E. J. et al. (1986) Hypertension knowledge, attitudes, and behavior: 1985 NHIS findings. Public health reports 101 , pp. 559-606.

24. Rosenbaum, W. A. (2008) Environmental politics and policy 7th ed, CQ Press, Washington, $\mathrm{DC}$

25. Russell, C. S. Portney, P. R. (ed) (1990) Monitoring and enforcement. Public policies for environmental protection pp. 234-274. Resources for the Future, Washington, DC

26. Salzman, J. and Thomson Jr, B. H. (2006) Environmental law and policy 2nd ed, Foundation Press, New York

27. San Francisco State University, Public Research Institute (2002) Outreach research - survey and focus groups: DIYers and used oil disposal: initial results and recommendations.

Publication No. 611-01-009 California Integrated Waste Management Board, Sacramento, CA 
28. San Francisco State University, Public Research Institute (2005) 'To the greatest extent possible': do-it-yourselfers and the recovery of used oil and filters. Publication No. 611-05008 California Integrated Waste Management Board, Sacramento, CA

29. Skinner, B. F. (1938) The behavior of organisms Appleton-Century-Crofts, New York

30. Skinner, B. F. (1953) Science and human behavior Macmillan, New York

31. Tabanico, J. J. and Schultz, P. W. (2007) Community-based social marketing. BioCycle 48 , pp. $41-44$.

32. US Congress, Office of Technology Assessment (1995) Environmental policy tools: a user's guide. OTA-ENV-634 US Government Printing Office, Washington, DC

33. US Department of Health and Human Services (1997) Toxicological profile for used mineralbased crankcase oil Public Health Service, Agency for Toxic Substances and Disease Registry, Atlanta

34. US Environmental Protection Agency (1989) Recycling used oil: what can you do? EPA/530SW-89-039B US Environmental Protection Agency, Office of Solid Waste and Emergency Response, Washington, DC

35. Winett, R. A. et al. (1985) Effects of television modeling on residential energy conservation. Journal of applied behavior analysis $\mathbf{1 8}$, pp. 33-44. 


\section{List of Tables}

Table 1. Used oil collected by public collection programmes in California (in millions of gallons) by fiscal year.

1994-95 1995-96 1996-97 1997-98 1998-99 1999-2000 2000-01 2001-02* 2002-03* 2003-04* 2004-05*

\begin{tabular}{|c|c|c|c|c|c|c|c|c|c|c|}
\hline Kerbside & 0.9 & 0.9 & 0.8 & 0.9 & 0.7 & 0.6 & 0.5 & 0.9 & 0.9 & 1.0 \\
\hline Form $303 * *$ & 0.6 & 0.7 & 1.0 & 0.8 & 0.9 & 1.1 & 0.9 & 1.0 & 1.0 & 1.0 \\
\hline Certified centres & 5.6 & 8.7 & 10.2 & 11.3 & 13.2 & 15.2 & 16.3 & 18.5 & 19.9 & 20.6 \\
\hline Total oil & 7.1 & 10.3 & 12.0 & 13.0 & 14.8 & 16.9 & 17.7 & 20.4 & 21.8 & 22.6 \\
\hline
\end{tabular}


Table 2. California lubricating oil sales and used lubricating oil recycling volumes (in millions of gallons) by fiscal year.

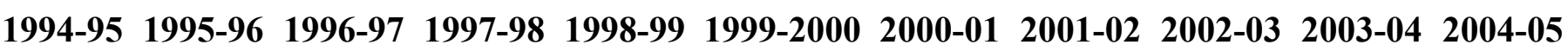

*Figures include used lubricating oil collected by public programs (about 25 percent) and from other sources, recycled both in and out of California.

Source: Adapted from California Integrated Waste Management Board (2006).

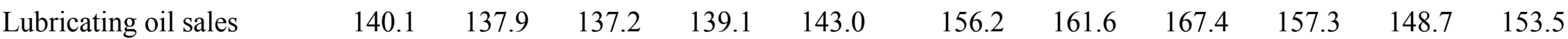

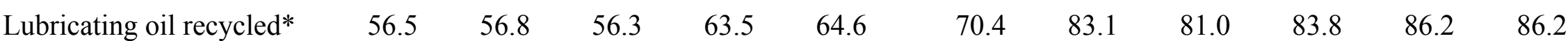


Table 3. Policy instruments used in California's used oil programme.

\section{Instrument}

Command and

control

Economic incentives

Recycling incentive

\section{Grant programmes}

Information/education Technical assistance

Statewide education and outreach

Local education and outreach

\section{Whose behaviour is targeted?}

Those who generate, store, transport, recycle or burn used oil beyond de minimus quantities

(excluding households)

Everyone

Used oil generators, including DIYers, fleet operators, service stations, fast-lubes, etc.

Local governments, non-profit organisations, other entities engaged in R\&D

Everyone

Everyone

Everyone
Direct or indirect

impact on DIYers

Indirect

Direct

Direct

Indirect

Direct

Direct

Direct 